\title{
Microstructural analysis of EN-GJS-450-10 ductile cast iron via vibrational casting
}

\author{
Çağlar Yüksel \\ Atatürk University, Department of Metallurgical and Materials Engineering, Erzurum, Turkey
}

\begin{abstract}
EN-GJS-450-10 ductile cast iron was produced with and without vibration to evaluate microstructural features. To investigate the effect of vibration, a reference, and two different castings having amplitudes of $0.9 \mathrm{~mm}$ and $1.8 \mathrm{~mm}$ were cast with a fixed vibration frequency of $50 \mathrm{~Hz}$. The nodule count (density), form (type), size distribution, nodularity, and the fraction of graphite, percentages of both ferrite and pearlite phases, length of ferrite shell, and pore, were evaluated via optical microscopy using an image analysis software. It is observed that the microstructure of the cast iron is more uniform by vibrational casting than that by non-vibrational casting. Additionally, mechanical vibration enhances nodule count and nodularity, also, more ferritic matrix could be obtained after the application of vibration. Nodule count and nodularity of vibrational casting with $1.8 \mathrm{~mm}$ amplitude increased from 226 nodule per $\mathrm{mm}^{2}$ and $80 \%$ to 311 nodule per $\mathrm{mm}^{2}$ and $86.5 \%$ of non-vibrational casting. Percentages of ferrite and graphite area dramatically improved from $24 \%$ and $16.5 \%$ for non-vibrational casting to $57 \%$ and $22.3 \%$ for vibrational casting with $1.8 \mathrm{~mm}$ amplitude, whereas the percentages of pearlite and pores decreased significantly from $56.1 \%$ and $5 \%$ to $20 \%$ and $1 \%$, respectively.
\end{abstract}

Key words: mechanical vibration; spheroidal cast iron; ductile iron; nodularity; image analysis; amplitude

CLC numbers: TG146.21 Document code: A

Article ID: 1672-6421 $202004-272-07$

$\mathrm{C}$ ast irons are the most widely used engineering materials in the world with $71 \%$ of total metal casting all over the world, followed by non-ferrous and steel castings with $17 \%$ and $9 \%$, respectively, following World Casting Census ${ }^{[1,2]}$. Among the cast iron family, ductile, or spheroidal cast irons exhibit outstanding properties, such as castability, strength/weight ratio, and corrosion resistance ${ }^{[3]}$. With these well-developed features, the production of ductile iron was increased substantially in the last decade comparing with other cast iron groups ${ }^{[2]}$. Also, ductile irons are suitable for mass production such as components of windmills ${ }^{[4-6]}$. Whether the matrix of the ductile iron will be ferritic, pearlitic, or both, the type of graphite could be controlled with the addition of alloying elements ${ }^{\text {[7-12] }}$.

Some other techniques, such as electromagnetic, ultrasonic vibrations were developed to modify the

\footnotetext{
*Çağlar Yüksel

Male, born in 1984. Ph. D., Assistant Professor. His research interests mainly focus on the casting of aluminum alloys, magnesium alloys, cast irons; solidification of alloys, and casting simulations. To date, he has published 11 technical papers in journals and 53 conference papers. He has been the researcher of many projects, such as the "Development of High-Strength Aluminum Alloys for Aerospace Applications", "Production of Metal Matrix Composites Reinforced with Carbides", "Application of ultrasonic degassing process to aluminum and its alloys", and so on.

E-mail: cyuksel@atauni.edu.tr

Received: 2020-04-23; Accepted: 2020-07-01
}

phases to obtain better properties of metals and alloys with the same chemical compositions ${ }^{[13-28]}$. Vivès ${ }^{[15]}$ studied the effect of electromagnetic vibrations on the continuous casting of aluminum alloys with regards to short and long solidification range alloys, 1085 and 2214, respectively. It was found that the grain size was refined when electromagnetic vibration was applied to the solidifying alloy. Radjai and Miwa ${ }^{[16]}$ demonstrated that electromagnetic vibration was also suitable for cast irons, such as gray iron. It is found that eutectic structures were almost completely refined, and the primary austenite structure became finer and homogeneous in the matrix. Also, the frequency range between 200 and $500 \mathrm{~Hz}$ was to be found favorable for cast irons. With applying ultrasonic treatment to the solidifying steels ${ }^{[18]}$ and magnesium alloys ${ }^{[19]}$, microstructures of the alloys were transformed from massive dendritic structure to finer equiaxed type. Voigt et al. ${ }^{[20]}$ reported that the nodule count and nodularity of the ductile iron with ultrasonic treatment increased slightly from 222 nodules per $\mathrm{mm}^{2}$ and $74 \%$ to 227 nodules per $\mathrm{mm}^{2}$ and $79 \%$, respectively.

In addition to these techniques, mechanical vibration is one of the most popular refinement methods for alloys. The first attempt was successfully done by Chernov in 1868 during steel solidification. Mechanical vibration was applied to achieve finer grains ${ }^{[21]}$. In recent times, attempts were implemented to aluminum 
and its alloys, and the majority of these studies focused on grain refining ${ }^{[22-25]}$. Vibrational casting routes are also used to produce feedstock for new generation casting methods, such as semi-solid metal casting ${ }^{[26]}$. Applying vibration to the cast metal under low amplitude and high frequency is favorable and also practical to produce defect-free castings. But both higher amplitude and frequency generally give rise to some casting problems, i.e., fluctuation of liquid metal, generation of gas bubbles, and mold erosion ${ }^{[27]}$. To date, the grain refinement, enhanced homogeneity, reduced segregation, and closer to the theoretical density of non-ferrous alloys could be achieved via vibrational casting. Nevertheless, it is important to note that for cast irons, stable and meta-stable solidification characteristics should also be considered ${ }^{[28]}$.

This study was performed to contribute to the gap in the literature about the vibrational casting of cast irons. It is aimed to clarify some features of the ductile cast iron grade ENGJS-450-10 during solidification under mechanical vibration.

\section{Materials and methods}

Seventy kilograms of EN-GJS-450-10 (GGG45) alloy was melted in the melting furnace. After melting, Mg-treatment was conducted on the transfer ladle via the tundish ladle to ensure $0.04 \mathrm{wt} . \% \mathrm{Mg}$ was achieved in the alloy. Then, the melt was transferred to a pouring ladle. Ce-based inoculant was used via the pouring stream inoculation technique. The chemical composition of EN-GJS-450-10 is given in Table 1.

Table 1: Chemical composition of EN-GJS-450-10 (wt.\%)

\begin{tabular}{ccccc}
$\mathrm{C}$ & $\mathrm{Si}$ & $\mathrm{Mn}$ & $\mathrm{Cr}$ & $\mathrm{Mg}$ \\
\hline 3.70 & 2.65 & 0.18 & 0.25 & 0.04 \\
$\mathrm{Ni}$ & $\mathrm{Cu}$ & $\mathrm{P}$ & $\mathrm{S}$ & $\mathrm{Fe}$ \\
\hline 0.02 & 0.15 & 0.03 & 0.01 & 93.2 \\
\hline
\end{tabular}

Finally, the melt was poured into the $\mathrm{CO}_{2}$-hardened sand molds (Fig. 1) at $1,550{ }^{\circ} \mathrm{C}$. Three molds, with each mold including six specimens, were prepared. One of the molds was for reference casting without vibration (NV), and the other two were cast under vibration with a fixed frequency of 50 $\mathrm{Hz}$ and the amplitudes of $0.9 \mathrm{~mm}$ and $1.8 \mathrm{~mm}$. The sizes of

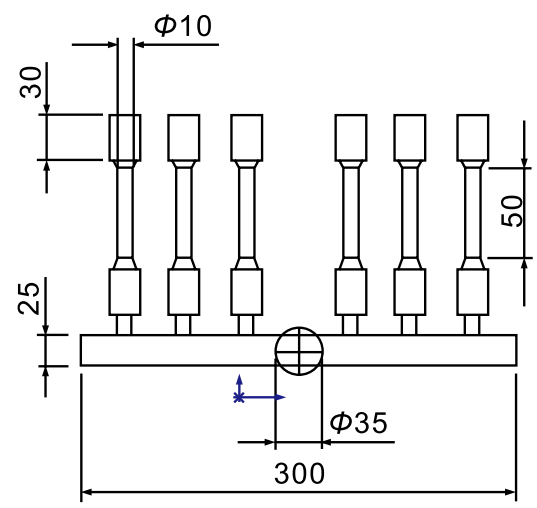

Fig. 1: Mold layout and size of specimens ( $\mathrm{mm})$ the specimens are according to ISO 1563. A sieve shaker was operated during casting as a source of mechanical vibration. Vibration is applied continuously to the molds for $300 \mathrm{~s}$ to assure appropriate solidification.

Graphite classification, interpreting of constituents of the matrix structures, and determination of nodularity in ductile iron were performed by both visual and image analysis in accordance with BS EN ISO 945-1 to 945-4 standards. An ImageJ image analyzer was employed to reveal the microstructural features of the ductile cast iron. Both the etched and un-etched microstructures were analyzed. Specimens were ground with 180, 400, 800, 1,000, and 1,200 grit SiC abrasive papers, and then were polished via $0.5 \mu \mathrm{m}$ alpha alumina powder. After revealing the morphology of the graphite nodules, all specimens were etched with $3 \%$ nital to reveal the percentages of pearlite and ferrite and ferrite shell. The shape, distribution, and size of graphite were investigated according to ISO 945-1 to 945-3 standards ${ }^{[29-31]}$. Additionally, the fraction and nodularity of the graphite were measured via ISO 945-4 ${ }^{[32]}$. Also, the nodule count per $\mathrm{mm}^{2}$ (nodule density), ratios of graphite, ferrite, pearlite, and pore were calculated via ImageJ image analyzer. The data were given as the averages of six samples analyzed.

\section{Results and discussion}

\subsection{Nodule count, form, size distribution and nodularity of graphite}

Nodule count or density has a strong effect on the thermal, corrosion and mechanical properties of ductile irons ${ }^{[4,33]}$. Furthermore, reducing chilling tendency, micro-segregation, and microstructural inhomogeneity in the final material could be ensured by the enhanced nodule density of the ductile iron ${ }^{[34,35]}$. Nodule count was calculated according to ISO 945-1:2019 and the average nodule densities of both non-vibrational and vibrational castings are given in Fig. 2. Non-vibrational casting has an average nodule count of 226 nodules per $\mathrm{mm}^{2}$, whereas $0.9 \mathrm{~mm}$ and $1.8 \mathrm{~mm}$ of vibrational castings have 262 and 311 nodules per $\mathrm{mm}^{2}$, respectively. It is important to note that there is a huge difference between the error bars of the castings: $0.9 \mathrm{~mm}$ amplitude of vibrational casting has a relatively large scatter of about 25 nodules in nodule count per $\mathrm{mm}^{2}$, however, increasing the amplitude of the mechanical vibration

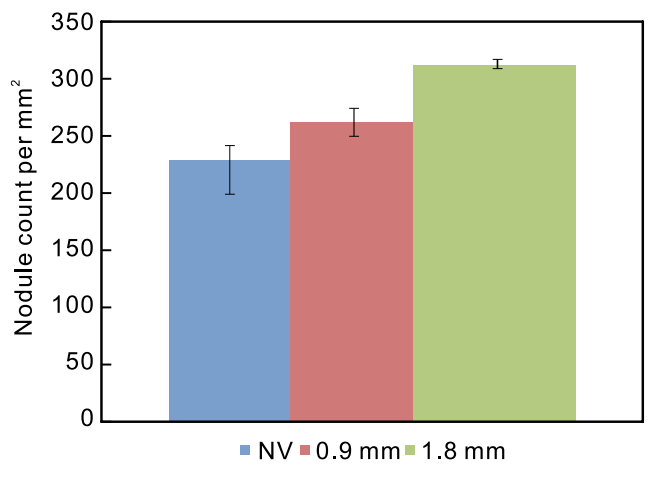

Fig. 2: Nodule density of castings of non-vibrational, and vibration with $0.9 \mathrm{~mm}$ and $1.8 \mathrm{~mm}$ of amplitudes 
gives a small scatter of approximately 7-8 nodules as well. On the other hand, non-vibrational casting has a dramatically large scatter of roughly 50 nodules. Thereby, the mechanical vibration gives more consistency in the nodule density than the non-vibrational casting.

The nucleation and growth of the graphite nodules during solidification are commonly known to be affected by the diffusion of carbon. Applying vibration to the casting could increase the kinetic energy and also the convection of the melt, thus atom mobility is increased ${ }^{[36,37]}$. This scenario is demonstrated in the vibrational castings. It can clearly be seen that the application of vibration to the casting could enhance the nodule count per unit area, and the nodule densities of the castings have an uptrend in terms of increasing vibration amplitude. The $0.9 \mathrm{~mm}$ and $1.8 \mathrm{~mm}$ amplitude of the vibrational castings have higher nodules than the nonvibrational casting with $15.9 \%$ and $37.6 \%$, respectively. Additionally, this indicates that an amplitude of $1.8 \mathrm{~mm}$ has a two-fold increase on the nodule count compared to $0.9 \mathrm{~mm}$. Voigt et al. ${ }^{[20]}$ obtained a higher nodule count and lower standard deviation of the nodule count using acoustic stimulation. It was observed that the nodule density and standard deviation were changed from 222 and 39 to 227 and 32 , respectively. It was also demonstrated that the grey cast iron could be attained without inoculation by using an ultrasonic device. In addition, theoretically, carbon could be grown both in liquid and solid, hence, the graphite particles become substantially larger ${ }^{[38]}$. As a consequence of the improved nodule count and the mechanical vibration (a factor influencing the nucleation and growth of graphite), finer graphite particles can be obtained.

According to ISO 945-1:2019, Form V graphites are the non-spheroidal graphite particles, whereas Form VI is fully nodular, and is the desired form to consider graphite as spheroidal ${ }^{[29]}$. The spheroidization technique (tundish ladle) is completely suitable to obtain nodular cast iron due to the residual $\mathrm{Mg}$ in the alloy. Moreover, the existing production methods are sufficient to achieve at least Form V or VI graphites. Thus, it is easily seen that the mechanical vibration does not directly affect the shape of the graphite nodules. However, achieving more globular graphite could propagate higher ductility and tensile strength ${ }^{[3,39]}$. As can be noticeably seen in Fig. 3, the graphite shapes of both non-vibrational and vibrational castings are fully spheroidal, which belong to Form VI. Additionally, circularity and roundness values can also be given to strengthen the shape factor values, obtained from the image analyzer. Both roundness and circularity values of nodules should greater than 0.6, according to ISO 945-4-2019.
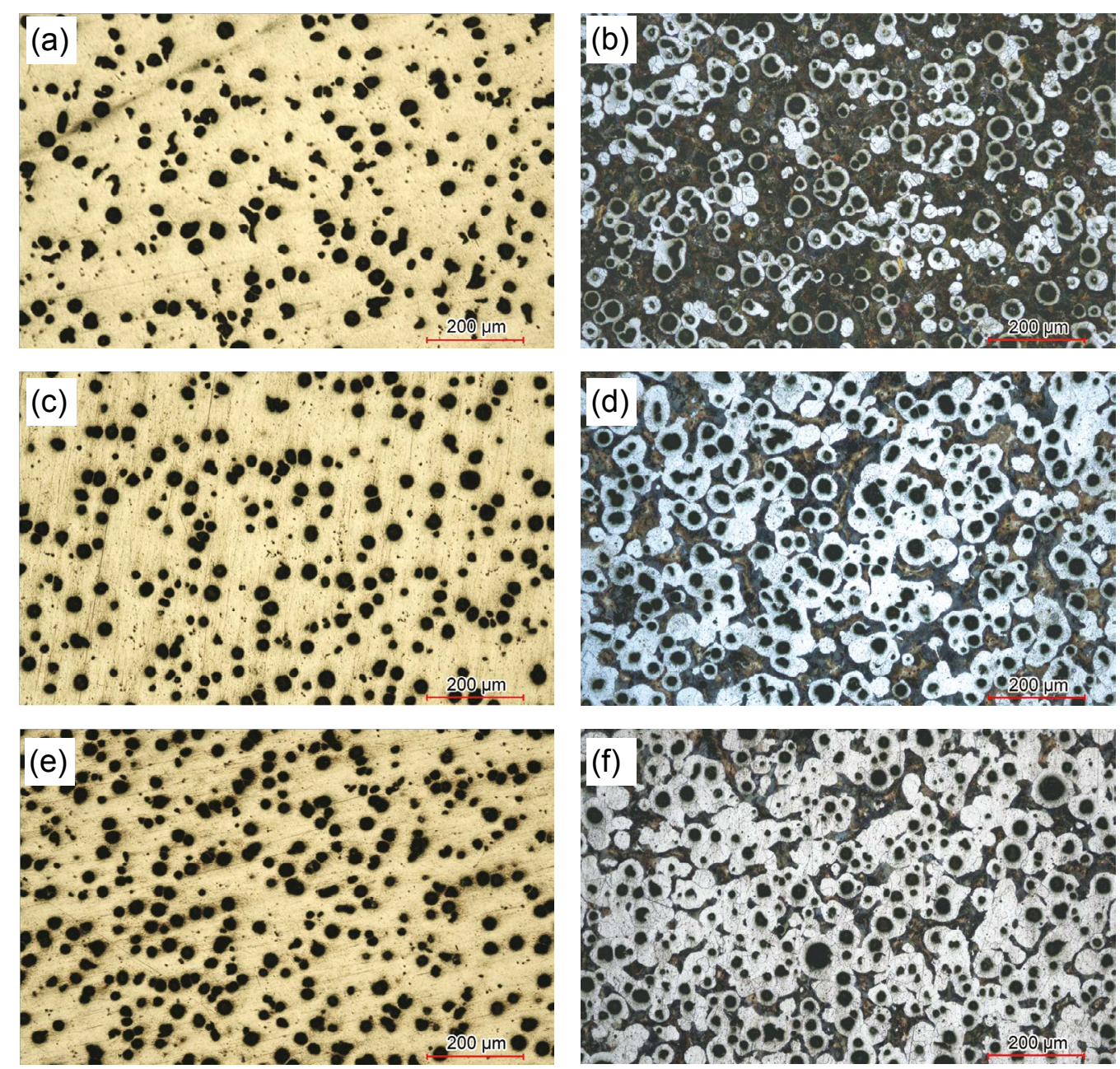

Fig. 3: Micrographs of unetched: (a) NV, (c) $0.9 \mathrm{~mm}$, and (e) $1.8 \mathrm{~mm}$, and etched samples: (b) NV, (d) $0.9 \mathrm{~mm}$, and (f) $1.8 \mathrm{~mm}$ 
Thus, the roundness and circularity values of all six specimens of the non-vibrational casting have, on average, $81 \%$ and $82 \%$ over 1,074 graphite particles. Furthermore, in six specimens of each condition, the roundness and circularity values for the vibrational casting of $0.9 \mathrm{~mm}$ and $1.8 \mathrm{~mm}$ amplitude are $83 \%$ and $84 \%$ over 1,474 nodules and $85 \%$ and $85 \%$ over 1,515 nodules, respectively.

The relevant standards ${ }^{[29-32]}$ show the size of the graphite nodules to be designated by the Arabic numerals 1 to 8 . Up to Range 6, which is equal to 30-60 microns, lower magnifications could be used to assess graphite size. However, for higher values than Range 6 to 8 , which meet the values of 1.5 microns, higher magnifications $(\times 200$ or higher) may be operated to evaluate the nodule size ${ }^{[29-33]}$. In ductile iron castings, foundry engineers make efforts to obtain at least Range 6 or higher to meet the mechanical properties demanded by the customer. Graphite size distribution imports all graphite particles in the measured area, on the contrary, nodule size distribution regards the particles fulfilling the nodularity of all graphite particles quantified ${ }^{[1,10,29-32]}$.

Size distributions of graphite and nodule are given in Fig. 4. In this figure, both vibrational and non-vibrational castings have totally achieved Range 6 or higher size distribution of the graphite (Fig. 4a) and nodules (Fig. 4b). In terms of the distribution of graphite size, non-vibrational casting has approximately $50 \%$ of Range $6,28 \%$ of Range $7,5 \%$ of Range 8 , and also approximately $17 \%$ of Range 5 . From the distribution of the graphite size of the non-vibrational casting of ductile iron, bimodal distributions of the graphite could be deduced ${ }^{[40]}$. Additionally, the vibrational castings of $0.9 \mathrm{~mm}$ and $1.8 \mathrm{~mm}$ amplitude have $60 \%$ of Range $6,25 \%$ of Range 7 , $5 \%$ of Range 8 ; and $58 \%$ of Range $6,35 \%$ of Range $7,5 \%$ of Range 8, respectively. In the light of this information, although both non-vibrational and vibrational castings have the graphite size of Range 6 on the average, both $0.9 \mathrm{~mm}$ and $1.8 \mathrm{~mm}$ amplitude of vibrational casting have uniformly and narrowly distributed graphite size class, whereas non-vibrational casting has the extensive distribution of graphite size class from 5 to 8 .
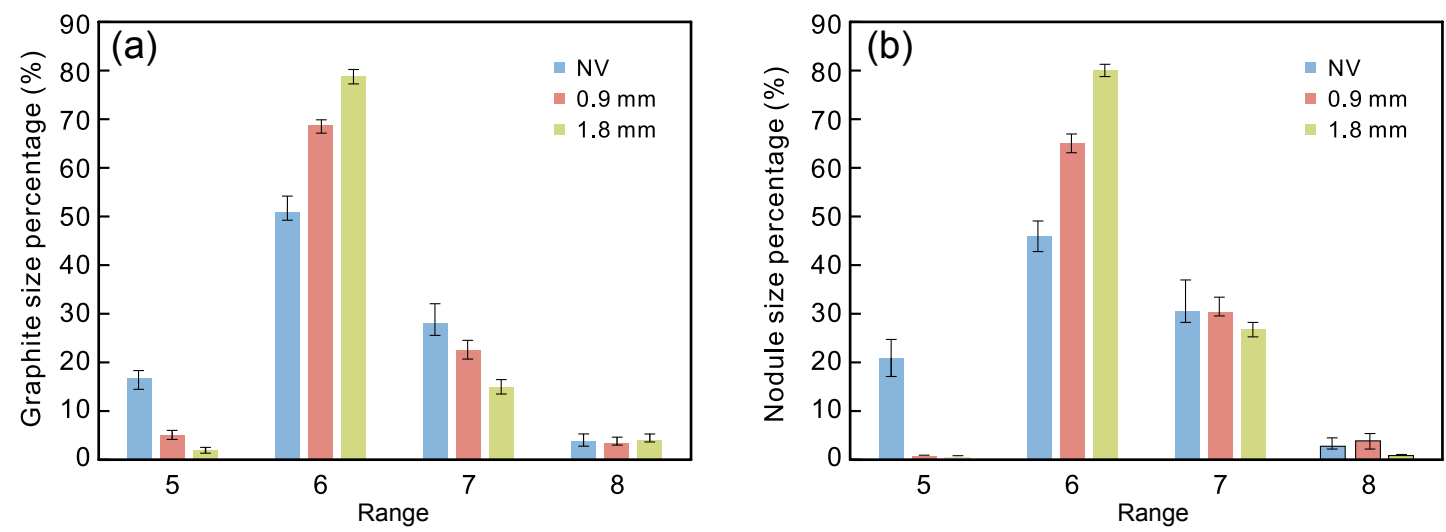

Fig. 4: Graphite (a) and nodule (b) size class distribution of non-vibrational (NV) and vibrational castings (0.9 and $1.8 \mathrm{~mm}$ amplitudes)

On the other hand, the nodule size distribution of nonvibrational casting has $40 \%$ of Range $6,30 \%$ of Range $7,2 \%$ of Range 8 , and also approximately $23 \%$ of Range 5 . This conventional casting method has a large scatter in the range of nodule size and standard deviations as well. By contrast, the vibrational casting method having amplitudes of 0.9 and $1.8 \mathrm{~mm}$ shows a lower scattering on both nodule size class distribution and standard deviation. The casting of $0.9 \mathrm{~mm}$ amplitude has nearly $50 \%$ of Range $6,30 \%$ of Range 7 , and $5 \%$ of Range 8 , whereas $1.8 \mathrm{~mm}$ amplitude casting has $80 \%$ of Range 6, 25\% of Range 7, and a minute amount of Range 8. There is a similar scenario in the graphite size distribution here. Thus, it could be said that in terms of both graphite and nodule size class distribution, the vibrational casting has 10$40 \mu \mathrm{m}$ of graphite diameter, while the non-vibrational casting has $10-80 \mu \mathrm{m}$. In addition, the vibrational casting yields a more homogenous distribution on both graphite and nodule size classes. The vibration amplitude and frequency directly affect the homogeneity of the phases ${ }^{[41]}$. Moreover, the size class distribution is strongly influenced by both thermal and corrosion resistance and wear properties of cast irons ${ }^{[33]}$. It is reported that after applying contactless ultrasonic treatment to the cast irons, the final diameter of the graphite particles could be refined as much as $13 \%$ over non-treated ones ${ }^{[20]}$

\subsection{Analysis of nodularity, graphite area, ferrite, pearlite, pore, and ferrite shell}

\subsubsection{Nodularity}

Nodularity is expressed by the number of nodular graphite particles divided by the total number of graphite particles in the microstructure of the cast iron, and is always reported as a percentage. However, in the standards, spheroidal or ductile cast irons typically executed a nodularity value at least $80 \%$ or higher, gray or flake cast irons $0 \%$, and compacted or vermicular cast irons have a nodularity degree between gray and ductile irons of 0 to $20 \%{ }^{[42]}$.

The nodularities of non-vibrational and vibrational castings were evaluated using ImageJ and are given in Fig. 5. As can be seen in this figure, the nodularity of both vibrational castings is increased with the ascendant amplitude of vibration. Nonvibrational casting has, on average, about $80 \%$ of nodularity with a relatively large standard deviation having a value of 


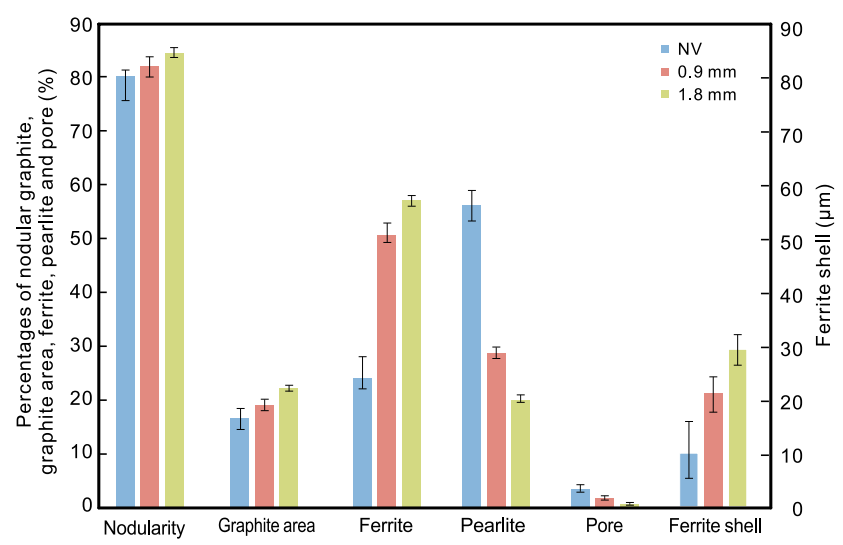

Fig. 5: Percentages of nodularity, graphite area, ferrite, pearlite, and pores and length of the ferrite shell of ductile iron with and without vibration

approximately 6 between maximum and minimum values through the non-vibrational casting, and the majority of these deviations are below $80 \%$. In contrast, using vibration on the castings assisted both to decrease the value of the standard deviation and to advance percentages of nodularity. Castings of $0.9 \mathrm{~mm}$ and $1.8 \mathrm{~mm}$ amplitudes have an average value of nodularity with $83 \%$ and $86.5 \%$ and of standard deviation with 3 and 2, respectively. Furthermore, in comparison with nonvibrational casting, the nodularity percentages of $0.9 \mathrm{~mm}$ and $1.8 \mathrm{~mm}$ amplitude castings are increased by $3.8 \%$ and $8.1 \%$, whereas the standard deviations of the castings dropped by $45 \%$ and $75 \%$, respectively. In applying vibration to the cast metals ${ }^{[13,44]}$, the basic harmonic motion creating periodic tension pressure in liquid metals could lead to improve nodularity, thus it enhanced mechanical properties, such as elongation, damping capacity, impact energy ${ }^{[44,45]}$.

\subsubsection{Graphite area}

In Fig. 5, the graphite area has an increasing trend like nodularity after mechanical vibration. In the non-vibrational casting, the percentage of graphite area is $16.5 \%$, whereas, in the vibrational castings, the amplitudes of $0.9 \mathrm{~mm}$ and $1.8 \mathrm{~mm}$ have $19 \%$ and $22.3 \%$, respectively. Additionally, the standard deviations of both the non-vibrational, and $0.9 \mathrm{~mm}$ and $1.8 \mathrm{~mm}$ amplitude vibrational castings are roughly 4,2 , and 1 , respectively. It is easily seen that the mechanical vibration ensures both more homogeneity and incremental graphite content. The area of graphite in turn is stimulated through mechanical vibration by percentages of $15.3 \%$ and $35.1 \%$, while decreasing the standard deviations $60.3 \%$ and $82.7 \%$ for the amplitude of $0.9 \mathrm{~mm}$ and $1.8 \mathrm{~mm}$. This improvement is correlated with ascending nodule density due to the amplitude of vibration. Since specimens were cast simultaneously, the microstructures are seen to have uniform solidification beside bimodal graphite and this can be detectable as seen in Fig. 3 .

\subsubsection{Ferrite, ferrite shell and pearlite}

The percentage of ferrite is increased with increased nodule count due to the formation of ferrite halos. On the other hand, pearlite percentages are descended by the proportionality of the constitution of these ferrite shells. This is the usual case of this type of ductile iron, having two matrix phases, namely ferrite, and pearlite. The percentage of ferrite is in turn $24 \%$ for non-vibrational, $50.4 \%$ for $0.9 \mathrm{~mm}$ amplitude, and $57 \%$ for $1.8 \mathrm{~mm}$ amplitude, whereas the percentages of pearlite are $56.1 \%$ for non-vibrational, $28.7 \%$ for $0.9 \mathrm{~mm}$ amplitude, and $20 \%$ for $1.8 \mathrm{~mm}$ amplitude. It is easily seen that after the mechanical vibration, the ferrite and pearlite phases were almost interchanged by each other. Moreover, the standard deviations of all castings have a decreasing trend from the non-vibrational to the vibrational casting. The standard deviations values of the ferrite phase having nearly 6,3 , and 2 with the development of $72.3 \%$ for $\mathrm{NV}$, amplitudes of $0.9 \mathrm{~mm}$, and $1.8 \mathrm{~mm}$, respectively. Whereas, the standard deviation values of the pearlite phase having about 6,2 , and 1 with development of $80 \%$ were calculated. Clearly, the mechanical vibration yields steady and homogenous microstructures.

Ferrite shell is enhanced with mechanical vibration from 10 $\mu \mathrm{m}$ to $30 \mu \mathrm{m}$ and the standard deviation values are decreased from 12 to 6 . In the non-vibrational casting, halos of ferrite have the smallest dimensions due to no agitation of the liquid metal. As was discussed previously, the vibration generates and enhances diffusion of carbon atoms which leads to an increased number of nodules; thus, the carbon depletion in the matrix aids the formation of ferrite. Conversely, the agitating metal during solidification, and also increasing vibration amplitude, result in increasing viscous drag forces on primarily solidified particles, and therefore giving rise to fragmentation. Further fragmentation could yield more ferritic structure due to the improvement of the nucleation rate of graphite ${ }^{[23]}$. The ferritic matrix was improved with increasing mechanical vibration. This could assist to produce more ferritic structure in critical issues, such as the production of windmill components. In these materials, EN-GJS-350-22-LT and EN-GJS-400-18U-LT, the ferritic structure is needed to ensure the higher elongation at fracture to meet standard properties of these materials ${ }^{[4,46]}$. To obtain a ferritic structure, mechanical vibration is applied without any chemical additives to the liquid metal or any further heat treatment procedures.

\subsubsection{Porosity}

According to researchers ${ }^{[47-49]}$, a diameter of less than $5 \mu \mathrm{m}$ pore could be negligible, since during the measurement via image analyzer this diameter may cause a misunderstanding whether it is a pore or particles of graphite or inclusion. Due to the fact that magnification of the micrographs was set to $\times 200$, the differentiation of pore and graphite becomes more prominent. The discrepancy between graphite nodules smaller than $5 \mu \mathrm{m}$ and pores was observed, and an accurate measurement of up to 10 microns has been attempted. In Fig. 5, it is easily seen that both percentages and standard deviation of the pores have a decreasing trend owing to the incremental amplitude of vibration. In the non-vibrational casting, the average percentage of the pore is about $5 \%$, whereas, in the vibrational casting, the pore percentages of the amplitudes of $0.9 \mathrm{~mm}$ and $1.8 \mathrm{~mm}$ are approximately $2.5 \%$ and $1 \%$, respectively. Usoltsev et al. ${ }^{[50]}$ carried out a vibration casting 
using different amplitudes from $0.5 \mathrm{~mm}$ to $3 \mathrm{~mm}$ in their work. They demonstrated that with improved amplitude of the vibration during solidification, porosity level of the aluminum alloys was gradually decreased, that is to say, the density of the material was increased, approximately $1.9 \%$, from $2.66 \mathrm{~g} \cdot \mathrm{cm}^{-3}$ to $2.71 \mathrm{~g} \cdot \mathrm{cm}^{-3}$, namely its theoretical value.

\section{Conclusions}

(1) Vibrational casting has a positive effect on microstructural phenomena, such as nodule count, nodularity. In addition, this phenomenon is further developed with an increasing level of vibration. Nodule count and nodularity of vibrational casting with $1.8 \mathrm{~mm}$ amplitude increased from 226 nodule per $\mathrm{mm}^{2}$ and $80 \%$ of non-vibrational casting to 311 nodule per $\mathrm{mm}^{2}$ and $86.5 \%$.

(2) Percentages of ferrite and graphite area dramatically improved from $24 \%$ and $16.5 \%$ for non-vibrational casting to $57 \%$ and $22.3 \%$ for virational casting with $1.8 \mathrm{~mm}$ amplitude, whereas the percentages of pearlite and pores decreased significantly through mechanical vibration from $56.1 \%$ and $5 \%$ to $20 \%$ and $1 \%$, respectively.

(3) The length of the ferrite shell also increased significantly from $10 \mu \mathrm{m}$ to $30 \mu \mathrm{m}$ via improved amplitude of the vibrational casting from $0.9 \mathrm{~mm}$ to $1.8 \mathrm{~mm}$ amplitude.

(4) Mechanical vibration is a practical method to improve the ferrite percentage of the matrix. This feature of mechanical vibration could be used in windmill production routes to obtain more ferritic matrix in ductile iron, such as EN-GJS-400-18U-LT.

\section{Acknowledgments}

The author specially thanks Prof. Dr. Derya Dispinar for valuable comments, guidance, and endorsement as always, Ugur Aybars Eser and Açelya Sandıkoğlu, and their company Ferro Döküm A.Ş. for procuring raw materials, and most particularly to Res. Ass. Ahmet Kabil and Ferhat Saydam for always assisting and supporting me in all circumstances, and experimental and characterization steps.

\section{References}

[1] Yüksel Ç. Production and structural characterization of wind turbine rotor hub. MSc Dissertation, Yildiz Technical University, 2011. (In Turkish)

[2] Nayyar V, Kaminski J, Kinnander A, et al. An experimental investigation of machinability of graphitic cast iron grades; flake, compacted and spheroidal graphite iron in continuous machining operations. Procedia Cirp, 2012, 1: 488-493.

[3] Elliott R. Cast iron technology. Butterworth-Heinemann, 1988: 1.

[4] Guzel E, Yuksel C, Bayrak Y, et al. Effect of section thickness on the microstructure and hardness of ductile cast iron. Materials Testing, 2014, 56(4): 285-288.

[5] Asensio L J, Álvarez A J F, Álvarez P C H. Microstructural optimization of unalloyed ductile cast irons with a ferritic matrix used in the manufacture of wind turbine rotors. Revista de Metalurgia, 2018, 54 (2): 1-9.
[6] Antolín J F Á, and Lozano J A. Optimization of the mechanical behaviour under tensile stress of spheroidal cast iron with ferritic matrix used in the manufacture of wind turbine hubs. International Journal of Metalcasting, 2017, 11(3): 513-522.

[7] González-Martínez R, De la Torre U, Ebel A. Effects of high silicon contents on graphite morphology and room temperature mechanical properties of as-cast ferritic ductile cast irons. Part II-Mechanical properties. Materials Science and Engineering: A, 2018, 712: 803-811.

[8] Labrecque C, and Gagne M. Ductile iron: Fifty years of continuous development. Canadian Metallurgical Quarterly, 1998, 37(5): 343-378.

[9] Davis J R (Ed.). ASM specialty handbook: Cast irons. ASM International, 1996.

[10] ASM Handbook. Volume 15: Casting. Materials Park: ASM International, 2008.

[11] Dekker L, Tonn B, and Lilienkamp G. Effect of antimony on graphite growth in ductile iron. International Journal of Metalcasting, 2020, 14(1): 1-9.

[12] Coy M, Russell K, Heidelberger E, et al. Effect of scandium on cast iron microstructure. International Journal of Metalcasting, 2020, 14(1): 275-277.

[13] Campbell J. Effects of vibration during solidification. International Metals Reviews, 1981, 26(1): 71-108.

[14] Guan R G, and Tie D. A review on grain refinement of aluminum alloys: progresses, challenges and prospects. Acta Metallurgica Sinica (English Letters), 2017, 30(5): 409-432.

[15] Vivès $C$. Effects of electromagnetic vibrations on the microstructure of continuously cast aluminium alloys. Materials Science and Engineering: A, 1993, 173(1-2): 169-172.

[16] Radjai A, and Miwa K. Structural refinement of gray iron by electromagnetic vibrations. Metallurgical and Materials Transactions A, 2002, 33(9): 3025-3030.

[17] Çolak M, and Kayikci R. The effect of electromagnetic stirring on the microstructural and mechanical properties of A356 casting alloy. Pamukkale University Journal of Engineering Sciences, 2009, 15(3): 345-351.

[18] Liang G, Shi C, Zhou Y, et al. Effect of ultrasonic treatment on the solidification microstructure of die-cast $35 \mathrm{CrMo}$ steel. Metals, 2016, 6(11): 260.

[19] Ning S, Chen X, Le Q, et al. Effect of ultrasonic frequency on cavitation behavior, microstructure and mechanical properties of AZ80 magnesium alloy. Materials Research Express, 2019, 6(8): 0865d9.

[20] Voigt R, Lynch P, and Grenko T. Cast iron solidification with non-contact acoustic stimulation. International Journal of Metalcasting, 2009, 3(4): 79-86.

[21] Chernov D. On the manufacture of steel, and the mode of working it. Journal of the Franklin Institute,1876, 102(3): 177-186.

[22] Fisher T P. Effects of vibrational energy on the solidification of aluminum alloys. British Foundryman, 1973, 66: 71-84.

[23] Taghavi F, Saghafian H, and Kharrazi Y H. Study on the effect of prolonged mechanical vibration on the grain refinement and density of A356 aluminum alloy. Materials \& Design, 2009 , 30(5): 1604-1611.

[24] Yüksel Ç. Effect of vibrational solidification on microstructure of primary and secondary Al7Si0.3Mg. Omer Halisdemir University Journal of Engineering Sciences, 2018, 7(2): 986992. (In Turkish)

[25] Koşatepe A, Kabil A, and Yüksel Ç. The effect of mechanical vibration on casting properties of grain refined A356 alloy. In: Proc. ICADET'19, Bayburt, 21-23 September, 2019.

[26] Limmaneevichitr C, Pongananpanya S, and Kajornchaiyakul J. Metallurgical structure of A356 aluminum alloy solidified under mechanical vibration: An investigation of alternative semi-solid casting routes. Materials \& Design, 2009, 30(9): 3925-3930. 
[27] Hasirci $\mathrm{H}$. Effects of microstructure and mechanical properties of ductile cast iron of mechanical vibration. Journal of Polytechnic, 2017, 20(2): 275-282.

[28] Xiao B T, Fan Z T, Jiang W M, et al. Microstructure and mechanical properties of ductile cast iron in lost foam casting with vibration. Journal of Iron and Steel Research International, 2014, 21(11): 1049-1054.

[29] Standard: BS EN ISO 945-1-2019, Microstructure of cast irons, Part 1: Graphite classification by visual analysis.

[30] Standard: PD ISO-TR 945-2-2011, Microstructure of cast irons, Part 2: Graphite classification by image analysis.

[31] Standard: PD ISO-TR 945-3-2016, Microstructure of cast irons, Part 3: Matrix structures.

[32] Standard: BS ISO 945-4-2019, Microstructure of cast irons, Part 4: Test method for evaluating nodularity in spheroidal graphite cast irons.

[33] Lekakh S, Qing J, Richards V, et al. Graphite nodule size distribution in ductile iron. In: Proc. 117th Metalcasting Congress, American Foundry Society, Schaumburg, IL USA, 2013.

[34] Fras E, Górny M, and Lopez H F. Chilling tendency and nodule count in ductile cast iron: Part I Theoretical background. AFS Transactions, 2006, 114: 575-594.

[35] Fras E, Gorny M, Lopez H F. Chilling tendency and nodule count in ductile cast iron Part II - Experimental verification. AFS Transactions, 2006, 114: 595-603.

[36] Pedersen K M, and Tiedje N. Nucleation and solidification of thin walled ductile iron - Experiments and numerical simulation. Materials Science and Engineering: A, 2005, 413: 358-362.

[37] Guo H M, Zhang A S, Yang X J, et al. Grain refinement of $\mathrm{Al}-5 \% \mathrm{Cu}$ aluminum alloy under mechanical vibration using meltable vibrating probe. Transactions of Nonferrous Metals Society of China, 2014, 24(8): 2489-2496.

[38] Kiani-Rashid A R, and Rounaghi S A. The new methods of graphite nodules detection in ductile cast iron. Materials and Manufacturing Processes, 2011, 26(2): 242-248.

[39] Minkoff I. The physical metallurgy of cast iron. New York: John Wiley and Sons, 1983: 102-112.
[40] Martinez M, Domengès $B$, Hug $E$, et al. Analysis of nuclei in a heavy-section nodular iron casting. Materials Science Forum, 2018, 925: 173-180.

[41] Xiao B T, Fan Z T, Jiang W M, et al. Effect of vibration frequency on primary phase and properties of grey cast iron fabricated by lost foam casting. China Foundry, 2020, 17(1): 1-7.

[42] ASTM A247-19, Standard Test Method for Evaluating the Microstructure of Graphite in Iron Castings.

[43] Guan R G, and Tie D. A review on grain refinement of aluminum alloys: progresses, challenges and prospects. Acta Metallurgica Sinica (English Letters), 2017, 30(5): 409-432.

[44] Al-Ghonamy A I, Ramadan M, Fathy N, et al. Effect of graphite nodularity on mechanical properties of ductile iron for waterworks fittings and accessories. International Journal of Civil Environment Engineering, 2010, 10: 1-5.

[45] Bauer B, Pokopec I M, Petrič M, et al. Effect of cooling rate on graphite morphology and mechanical properties in high-silicon ductile iron castings. International Journal of Metalcasting, 2020(1): 1-7.

[46] Roedter H, and Gagne M. Ductile iron for heavy section wind mill castings: a European experience. 2003 Keith Millis Symposium on Ductile Cast Iron, 2003.

[47] Ruxanda R E, Stefanescu D M, and Piwonka T S. Microstructure characterization of ductile thin-wall iron castings. AFS Transactions, 2002, 2: 1131-1148.

[48] Lacaze J, Castro M, and Lesoult G. Solidification of spheroidal graphite cast irons - II. Numerical simulation. Acta Materialia, 1998, 46(3): 997-1010.

[49] Domeij B, Hernando J C, and Diószegi A. Size distribution of graphite nodules in hypereutectic cast irons of varying nodularity. Metallurgical and Materials Transactions B, 2018, 49(5): 2487-2504.

[50] Usoltsev A A, Knyazev S V, Kutsenko A I, et al. Vibration influence on structure and density of aluminum alloys. Materials Science and Engineering, 2016, 150(1): 012027. 